\title{
INTERVENÇÃO HUMANITÁRIA E DIREITO INTERNACIONAL HUMANITÁRIO: PARADOXOS JURÍDICO-POLÍTICOS DO SÉCULO XXI
}

\author{
Ana Letícia Barauna Duarte Medeiros*
}

RESUMO: A partir do início dos anos 80 múltiplos conflitos armados intensificam as divergências econômicas, políticas, jurídicas entre países por vezes internamente já conturbados, prenunciando um complexo cenário na esfera do direito e das relações internacionais para o início deste milênio. A partir dessa constatação, o objetivo deste artigo é refletir acerca da atuação da ONU diante deste caótico panorama, confrontando as teorias do realismo político e do idealismo, bem como distinguir criticamente o polêmico conceito de intervenção humanitária do importante papel que hoje desempenha o chamado direito internacional humanitário

\section{INTRODUÇÃO}

Os episódios históricos vivenciados pelos "viajantes de olhos abertos"1 durante todo o século XX e o início deste novo

\footnotetext{
* Doutoranda em "Direitos Humanos e Democracia" e Mestre em "Direito do Estado" na Universidade Federal do Paraná (UFPR); Professora no curso de Direito da Pontifícia Universidade Católica do Paraná (PUC/PR).

${ }^{1}$ HOBSBAWN, Eric. A era dos extremos: o breve século XX: 1914-1921. 2. ed., 12 ${ }^{a}$ reimp. São Paulo: Companhia das Letras, 1995, p. 8. Terminologia empregada pelo autor para designar as pessoas (os estudiosos em especial) que têm como objeto de pesquisa o contexto histórico em que vivem, e não exclusivamente eventos ocorridos no passado. Também no dizer do autor, são os chamados "observadores participantes".
}

milênio evidenciam a presença cada vez mais crescente de situações que envolvem conflitos armados. Da Revolução Bolchevique, passando por duas Grandes Guerras de proporções mundiais, das lutas pela descolonização pós-45 às lembranças das tensões provocadas pela bipolar Guerra Fria, dos inúmeros conflitos étnico-civis que desembocaram em guerras internas em países já massacrados pela miséria até a emergência dos novos fundamentalismos e das ações terroristas, resta pouco espaço para argumentar sobre a possibilidade de um mundo senão de paz, pelo menos mais próximo dela.

Como pensar um mundo "pós-11 de setembro" sem os conflitos armados? Eis o 
desafio que apresentam os doutrinadores contemporâneos. Se para uns, as guerras são inevitáveis, e o poder unilateral norteamericano tenderá a se ampliar cada vez mais, através de uma visão maniqueísta e maquiavélica do chamado "governo global”, para outros a globalização há de ressurgir a partir da crença nos direitos humanos, nos princípios da não-violência, do respeito às organizações internacionais que visam à manutenção da paz - como as Nações Unidas -, e mais, na crença em um direito internacional e interno com concepções pacifistas.

\section{CONFLITOS ARMADOS NO CENÁRIO CONTEMPORÂNEO}

As décadas de 1980, 1990 e o início do século XXI revelam um trágico panorama a partir de uma análise dos episódios de guerra entre nações nos mais diversos lugares do planeta, e por causas que vem desafiando os analistas das relações internacionais. Em meados de 1980, a antiga União Soviética invadiu o Afeganistão, dando início a uma complexa disputa, envolvendo também os Estados Unidos e o Paquistão, até abril de 1988, quando por força da aplicação das Convenções de Genebra, um "cessar-fogo" foi atingido; na mesma época, setembro de 1980, o Iraque dá início a uma guerra contra o Irã, logo após os distúrbios internos havidos por conta da revolução islâmica iraniana, ${ }^{2}$

${ }^{2}$ Crise política no Estado do Irã que culmina, em abril de 1979, com a queda do regime do Xá Rexa Palevi e com a declaração oficial do Irã como uma república islâmica, cuja autoridade suprema é um chefe religioso (aiatolá), posto ocupado por Ruhollah Khomeini. Inicialmente foi eleito para presidência, em janeiro de 1980, Abolhasan Bani-Sadr, um dos líderes da oposição laica ao governo de Pahlevi. com o retorno à paz somente em agosto de 1988, supervisionado por uma Operação de Paz das Nações Unidas (conhecida pela sigla UNIIMOG).

Em $1990,{ }^{3}$ após a queda do Muro de Berlim em 1989, o mundo prestou particular atenção nas regiões dos Bálcãs e no chamado Golfo Persa. Na península balcânica, uma sucessão de múltiplas disputas eclodiu, em especial após os episódios que se sucederam à desintegração da Iugoslávia. A autodeclaração de independência da Croácia e da Eslovênia, em 1991, recebeu reconhecimento imediato da Alemanha recém reunificada e de alguns poucos receosos países europeus, ao mesmo tempo em que a Sérvia, buscando a manutenção da federação Iugoslava, declarou guerra à Croácia, num conflito que se espalhou rapidamente pela Bósnia-Hezergóvina. Logo em seguida, a Macedônia se declara independente, e Montenegro, a partir da organização de um plebiscito, decide permanecer na Iugoslávia.

Impossibililtada de sustentar a manutenção da antiga Iugoslávia, a Sérvia, então governada por Milosevic, promove ataques contra a Croácia e a Bósnia, provocando a rivalidade entre diferentes grupos étnicos (os sérvios cristãos ortodoxos -, os croatas - católicos romanos - e os bósnios - muçulmanos) especialmente no território da Bósnia - a tão comentada Guerra da Bósnia. O conflito

\footnotetext{
${ }^{3}$ Ressalta-se que, para fins deste estudo, deu-se preferência para os episódios que cronologicamente culminaram com a chamada "intervenção humanitária" no Iraque, o que não diminui em importância os múltiplos conflitos que a própria ONU acabou intervindo, como por exemplo, no Cambodia, no Timor Leste, em Angola, em Serra Leoa, no Haiti, dentre outros.
} 
se prolongou até dezembro de 1995, com a assinatura dos Acordos de Dayton, tornando-se o episódio mais violento vivenciado na Europa depois da Segunda Grande Guerra, com mais de 200 mil mortos, segundo estatísticas da ONU.

Entretanto, a paz não retornou definitivamente à região, na medida em que, pós-1995, permaneceu uma tensão entre os separatistas do Kosovo (Exército de Libertação do Kosovo), cuja população era formada majoritariamente por albaneses, e as forças sérvias lideradas por Milosevic. Por pressão da OTAN (Organização do Tratado do Atlântico Norte), Milosevic decreta “cessar-fogo" em novembro de 1998, mas os massacres contra os albaneses ${ }^{4}$ prosseguem até a intervenção da OTAN, em conjunto com a Operação "Força Aliada" liderada pelos Estados Unidos, em março de 1999, quando então Milosevic aceita a rendição. Contudo, ainda não convencido da derrota política sofrida nas urnas em setembro de 2000, pelo oposicionista Vojislav Kostunica, o exditador tenta de todas as formas retornar ao

\footnotetext{
${ }^{4}$ ORGANIZAÇÃO DAS NAÇÕES UNIDAS. Main UN Bodies. Disponível em: <http://www.un.org/icty/ index.html> Acessado em: 20 abr. 2006. Para julgamento das atrocidades cometidas na ex-Iugoslávia desde 1991, a ONU procedeu à criação de um Tribunal temporário (YCTI - International Criminal Court for the former Yugoslavia), através da Resolução 827 de 25 de março de 1993 de seu Conselho de Segurança. O tribunal indiciou 161 pessoas por graves violações a normas de direitos humanos e de direito internacional humanitário grave violação das Convenções de Genebra, violações do direito e dos costumes de guerra, genocídio e crimes contra a humanidade - cometidas no interior do território da antiga Iugoslávia, dentre eles o ditador Slobodan Milosevic, que veio a falecer em 11 de março de 1996, antes de receber sua sentença final.
}

poder, somente reconhecendo sua ruína forçado pelo povo, que toma o centro de Belgrado em 05 de outubro clamando por justiça e democracia.

O início dos anos 90 também foi profundamente abalado pela invasão do Iraque ao Kuwait, comandada por Saddam Hussein, motivado pela baixa do preço do petróleo em razão da venda do produto a preços mais baixos do que a cota estipulada pela OPEP (Organização dos Países Exportadores do Petróleo). ${ }^{5}$ A complexidade das questões econômicas, aliada ao "braçode-ferro" de Saddam, fez com que o Iraque, mesmo diante do embargo comercial que lhe foi decretado pela ONU, anexasse o país vizinho, provocando a morte de milhares de pessoas até o fim da ocupação, por obra da "Operação Tempestade no Deserto", constituída por forças coligadas de mais de 30 países, liderados pelos EUA.

Durante toda a década em análise, a ONU vem atuando na região, com o objetivo de diminuir as tensões internas entre curdos, árabes xiitas, árabes sunitas, dentre outros grupos menores, além de fazer inspeções para destruição de eventuais armas químicas, biológicas e nucleares existentes, sendo que a primeira ocorre em 1993, através da Comissão Especial das Nações Unidas

${ }^{5}$ ORGANIZAÇÃO DOS PAÍSES EXPORTADORES DE PETRÓLEO. Disponível em: <http://www.opec.org/ home>. Acessado em: 03 abr. 2006. A Organização foi criada em 1960, com o objetivo de administrar de forma centralizada a política petroleira de seus membros - Arábia Saudita, Argélia, Catar, Emirados Árabes Unidos, Indonésia, Irã, Iraque, Kuwait, Líbia, Nigéria e Venezuela. Atualmente a organização responde por $2 / 3$ das reservas conhecidas de petróleo de detém mais da metade das exportações mundiais do mineral. 
(UNSCOM), e a segunda, em 1999, denominada Comissão para Monitoramento, Verificação e Inspeção (UNMOVIC), logo após a operação militar "Raposa do Deserto" de dezembro de 1998, comandada por EUA e Reino Unido, quando o Iraque foi bombardeado por mísseis durante 70 horas ininterruptas, sob alegação de violação dos acordos até então feitos.

As tensões no Oriente Médio permaneceram inconstantes e múltiplas até que, em 11 de setembro de 2001, num ataque meticulosamente executado e com alvos escolhidos cautelosamente, terroristas islâmicos do grupo "Al Qaeda", 6 cujo líder principal, Osama Bin Laden, é notícia em todos os jornais do mundo até hoje, 19 homens, com passaportes de países árabes, seqüestraram quatro aviões de passageiros norte-americanos para utilizá-los como mísseis. Os alvos escolhidos foram: as "torres gêmeas do World Trade Center", em Nova York, símbolos do poderio econômico norte-americano, destruídas quase que simultaneamente por dois dos aviões; a sede administrativa de seu poder militar, o Pentágono, em Washington, atingida por um $3^{\circ}$ avião; e segundo notícias da época, a $4^{\mathrm{a}}$ aeronave seqüestrada caiu a caminho da Casa Branca, o palácio residencial do presidente norte-americano.

\footnotetext{
${ }^{6}$ Formada por militares islâmicos recrutados em vários países, a organização terrorista $\mathrm{Al}$ Qaeda (que significa "a base" em árabe) foi criada por Osama Bin Laden em 1989, um saudita que participara da luta contra a invasão do Afeganistão pela ex-URSS, com armas e treinamentos do próprio Estados Unidos. As relações entre Bin Laden e os norteamericanos começam a se deteriorar em 1990, com a eclosão da Guerra do Golfo. Apesar de se opor a invasão do Kuwait pelo Iraque, ele não aceita a presença de soldados norte-americanos na península arábica, berço do profeta Maomé e sede dos principais santuários islâmicos.
}

Este episódio marca significativamente o ingresso de novos componentes ao panorama de conflitos no mundo: o terrorismo e o fundamentalismo. Nesse sentido, atos terroristas não estão necessariamente ligados a grupos fundamentalistas, na medida em que os objetivos podem ser distintos, como movimentos separatistas, e pode até mesmo estar ligado a atos de Estado, como é clássico o exemplo do "terror sistêmico" provocado pelos regimes totalitaristas de direita e de esquerda, consoante bem trabalha Hannah Arendt, em sua obra Origens do totalitarismo. Por outro lado, o fundamentalismo também não pode ser considerado necessariamente de origem religiosa, muito embora a xenofobia aos muçulmanos possa ter contribuído decisivamente para que tais grupos ganhem força no mundo atual. ${ }^{7}$

Diante dos ataques, o presidente norteamericano George W. Bush inicia sua "guerra contra o terror", reinaugurando um tipo de discurso que reduz os interesses do planeta a uma luta entre "o bem e o mal". Logo após o trágico episódio, que deixou um saldo final de mais de 2.500 norte-americanos e alguns estrangeiros mortos, ingressou numa cruzada contra seu alvo primeiro: o regime talibã no Afeganistão, que segundo os EUA, abrigava organizações acusadas de cometer os atentados. O objetivo principal era de domínio público: depor o regime, desmantelar a $\mathrm{Al}$ Qaeda e capturar Bin Laden. Em poucos meses o regime autoritário foi deposto, um governo interino assumiu o controle por 6

7 Sobre o assunto consultar: ALI, Tariq. Confronto de fundamentalismos: cruzadas, jihads e modernidade. Rio de Janeiro: Record, 2002. 
meses, a partir de dezembro de 2001, e em janeiro de 2002, cerca de 5 mil soldados da Força Internacional de Segurança para o Afeganistão (ISAF) da ONU chegaram ao país. A reconstrução do país, geográfica e politicamente tem se mostrado muito complexa, mas o principal alvo do pânico norte-americano, Bin Laden, até o momento não foi capturado.

Desde a intervenção dos EUA no Afeganistão, o governo norte-americano vinha defendendo a idéia de que o próximo passo da chamada "guerra contra o terror" deveria ser uma ação militar para depor o ditador iraquiano Saddam Hussein. Nesse contexto, George Bush chegou a incluir, em janeiro de 2002, o Iraque, ao lado do Irã e da Coréia do Norte, entre os países de um pretenso "eixo do mal", acusando-os de apoio ao terrorismo e acúmulo de armas de destruição em massa. Conforme crítica de Tariq Ali ${ }^{8}$ :

(...) Saddam Hussein, anteriormente aliado de Washington, era agora rotulado de "Hitler árabe”. A mídia do Ocidente pegou o refrão e os governantes venais do pequenino Kuwait tornaram-se parte de uma ofensiva de propaganda. (...) Depois dos acontecimentos de 11 de setembro os planejadores do Pentágono levantaram de novo a questão de retirar Saddam Hussein do poder. Se for lançada uma nova guerra contra o Iraque, a chamada "Guerra contra o Terrorismo" irá se transformar no oposto. A combinação de raiva e desespero levará a um número cada vez maior de jovens no mundo árabe e em outros lugares sentindo que a única reação ao terrorismo de Estado é o terrorismo individual.

8 ALI, Tariq. Confronto de fundamentalismos..., p. 202 .
A fala dura e radical de Ali infelizmente tem se traduzido na mais pura realidade. Os Estados Unidos, auxiliados pelo Reino Unido, desde 2002 começaram uma intensa campanha acusando o Iraque de violação das resoluções da ONU sobre armas. No início de 2003, George W. Bush e o primeiroministro inglês Tony Blair começaram a pressionar o Conselho de Segurança das Nações Unidas para que fosse aprovada uma resolução autorizando o uso da força para o desarmamento do Iraque. Contudo, enfrentaram forte resistência de outros países que, liderados pela França, preferiram conceder mais tempo para que a UNMOVIC concluísse sua tarefa de inspeção. Mas o impasse instaurado no Conselho de Segurança acabou culminando com a decisão unilateral portanto, sem a autorização do Conselho dos EUA e do Reino Unido de atacar o Iraque, o que acabou dando início a uma guerra em 19 de março de 2003.

Para Wolfgang Kersting, ${ }^{9}$ entretanto, o mundo não pode deixar se enganar "pela autoridade moral reivindicada: por meio dessa intervenção militar com fins de proteção aos direitos humanos, a guerra ofensiva está de volta ao direito internacional". A situação no território iraquiano até hoje é muito delicada, culminando com a detenção do ditador Hussein e inúmeras mortes de civis, militares e ativistas da paz, inclusive a do diplomata brasileiro Sérgio Vieira de Mello, que lá estava a serviço do Alto Comissariado da ONU para os Direitos Humanos.

${ }^{9}$ KERSTING, Wolfgang. Hobbes, Kant, a Paz Universal e a guerra contra o Iraque. Kant e-Prints v.3, n.2, 2004 , p.5. 


\section{O POlÊMico CONSElHo de SEGURANÇA E AS CRÍTICAS ATUAIS}

Embora se possa na esfera teórica questionar a justiça ou a injustiça da ocorrência ou não de uma guerra, no plano do direito internacional cabe ao Conselho de Segurança da ONU decidir, em última análise, a legalidade/legitimidade de uma intervenção e da conseqüente ocorrência de um conflito armado no mundo de hoje. De acordo com os artigos 24, 41 e 42 da Carta das Nações Unidas, este órgão tem autoridade para examinar qualquer conflito ou disputa que possa ter repercussões internacionais. Nesse contexto, o Conselho pode identificar uma ação agressiva de um Estado e chamar os membros das Nações Unidas para tomarem as atitudes devidas, incluindo a aplicação de sanções econômicas e até se valer do uso de ações militares, o que acaba fazendo com que seus membros fiquem de prontidão para uma eventual deliberação a qualquer momento. ${ }^{10}$

A questão que se apresenta como polêmica ao tratar do assunto se deve ao fato de o Conselho de Segurança ser o único órgão da ONU cujas resoluções têm poder legal de veto, situação esta que se acentua na medida em que possui membros permanentes desde a sua criação, isto é, um imenso poder de decisão nas mãos de alguns poucos Estados. Assim, o Conselho possui 15 membros, dez deles eleitos pela Assembléia Geral para mandatos de dois anos, e os outros cinco restantes, com caráter permanente, o que

${ }^{10}$ FASULO, Linda. An insider's guide to the UN. USA: Yale Univesity Press; Vail-Ballou Press, 2004, p.39-51. acaba lhes conferindo verdadeiramente o poder de veto sobre o tema das resoluções (basta que um dos membros permanentes discorde de alguma questão para que uma resolução não seja aprovada). Os "cinco Permanentes" são: China, França, Rússia, Reino Unido e EUA; ao passo que os membros não-permanentes serão eleitos na seguinte proporção: três Africanos, dois Latinoamericanos; um Árabe, um Asiático, um Europeu Ocidental e 01 Europeu Oriental.

Não se pode esquecer, contudo, que em muitos momentos, em atuações conjuntas com o Secretário-Geral, o Conselho obteve sucesso ao supervisionar políticas públicas em locais como a Namíbia na África e a América Central entre as décadas de 80 e 90. O resultado, em ambos os casos, foi positivo, com a independência da Namíbia e avanços significativos para a reconciliação definitiva entre El Salvador e a Nicarágua, o que também acabou ocorrendo com a reorganização jurídico-política e a questão da fome na Somália, entre 1992 e 1993, dentre outros exemplos positivos que aqui poderiam ser citados. ${ }^{11}$

Portanto, é a partir desse contexto que se pode considerar uma intervenção militar legítima ou não, como é juridicamente positivo o exemplo da intervenção da OTAN no Kosovo, autorizada pela Resolução 1244 de 1999. O ápice da polêmica ocorreu, entretanto, por ocasião da reunião da Assembléia Geral em Setembro de 2002, quando então o Presidente dos EUA George

11 WEISS, Thomas G.; FORSYTHE, David P.; COATE, Roger A. The United Nations and changing world politics. 4th ed. Colorado: Westview Press, 2004, p.336-337. 
W. Bush desafiou as Nações Unidas, desrespeitando a resolução que desaprovava a invasão norte-americana no continente iraquiano, tendo ao seu lado o Reino Unido. A crise gerada dentro da organização, em virtude do desrespeito e do descrédito que a guerra gerada provocou em todas as partes do mundo, tem trazido à tona o clamor por uma necessária reforma das Nações Unidas. O mundo no século XXI é radicalmente distinto daquele pós Segunda Grande Guerra, e não há justificativas admissíveis para que não se repense as funções e os próprios órgãos da ONU diante dos recentes acontecimentos.

Contudo, não se adota para fins deste trabalho uma postura de que a ONU se tornou obsoleta e, portanto, desnecessária para a manutenção da paz e do respeito aos direitos humanos. Muito ao contrário, mais do que nunca uma organização de caráter cosmopolita deve ser considerada, mas os novos desafios que se apresentam devem ser considerados suficientemente reveladores para que a instituição trabalhe suas premissas a partir da utilização de métodos mais condizentes com a diversidade cultural, com a tecnologia e com as rápidas transformações econômicas e sócio-ambientais que se avizinham.

\section{INTERVENÇÃO HUMANITÁRIA: GUERRA JUSTA OU INJUSTA?}

A guerra dos EUA e alguns aliados contra o governo iraquiano evidenciou a temática da intervenção humanitária na interdisciplinaridade que comporta, em especial, o estudo do direito, da ciência política, da economia e das relações internacionais. Intelectuais do mundo todo restaram abismados diante da justificativa "democrática e em nome dos direitos humanos" utilizada pelo governo norteamericano para sustentar o seu desrespeito às Nações Unidas. Para dizer o mínimo, "seu status de legitimidade nem é discutível, como se pode ouvir às vezes. Ao contrário, sua legitimidade é indiscutível. A guerra do governo de Washington contra o regime do Iraque é uma inequívoca violação do direito internacional. Pior ainda, sendo uma força ilegítima ela é uma violação dos princípios do direito. A destruição do direito, realizada por ela, desmente, desde o início, aqueles nobres fins por ela propagados". ${ }^{12}$

Nesse contexto, a própria vagueza das regras das políticas mundiais têm sido uma constante, o que por si só não legitimaria a guerra no Iraque. De qualquer forma, é importante citar que nem a Corte Internacional de Justiça da ONU, tampouco o Conselho de Segurança, especificaram a distinção entre uma "ruptura de paz" e uma "agressão ilegítima/não autorizada". Por outro lado, o próprio termo "intervenção" nunca foi oficialmente definido. Assim, ainda que uma Assembléia Geral em 1974 tenha tentado conceituar agressão, muitas ambigüidades ainda permanecem, restando a questão atualmente sob a égide do Estatuto de Roma de 1998. Ademais, "seriam as represálias legais, em tempo de paz, dado que a Carta da ONU condena a ameaça ou o uso de força na ausência de um ataque armado? O uso da força seria autorizado com a justificativa de implementação de direitos? Poderia uma organização regional empregar a força sem a

12 KERSTING, Wolfgang. Hobbes, Kant, a Paz Universal..., p.9. 
prévia autorização do Conselho de Segurança? Respostas claras a estas e outras perguntas poderiam contribuir para o esclarecimento de muitos atuais questionamentos". ${ }^{13}$

$\mathrm{O}$ assunto nos remete ainda, no plano teórico, ao debate entre a chamada "guerra justa e injusta". Não é de hoje que se discute a questão, podendo ser situada, historicamente, no contexto da filosofia cristã medieval, responsável pela análise intrínseca da justiça da guerra, consagrando-se a partir das obras de Santo Tomás de Aquino, Francisco de Vitória e Suarez. De acordo com Celso Albuquerque Mello ${ }^{14}$ :

A apreciação final que se pode fazer da doutrina católica da guerra justa é que desde a sua origem ela procurou condenar uma série de guerras que não preenchiam determinadas condições. Esta doutrina atendia de certo modo ao pacifismo ao fazer a condenação das guerras injustas. Ela procurava limitar o poder dos Estados e príncipes que até o período entre as duas guerras mundiais não tinham neste domínio ou limitação do Direito Internacional Público positivo, vez que este não se interessava pela justiça da causa da guerra. Tanto assim era que a doutrina da guerra justa no século XVIII era considerada um doutrina moral.

No contexto atual, trata-se de falar de um conceito material de justiça ou injustiça

13 Tradução livre: "Moreover, are reprisals legal in peacetime given that the UN Charter has outlawed the threat or use of force in the absence of an armed attack? Can force be used to implement legal rights? Can a regional organization employ force without prior authorization from the Security Council? These and other questions about security rules could benefit from clearer answers." WEISS, Thomas G.; FORSYTHE, David P.; COATE, Roger A. The United Nations and changing..., p.333.

14 MELLO, Celso Albuquerque. Guerra Justa. In: BARRETO, Vicente de Paulo. Dicionário de filosofia do direito. São Leopoldo: Unisinos; Rio de Janeiro: Renovar, 2006, p.394. da guerra associado a uma concepção radical de violência, ou seja, é necessário mais do que argumentos de ordem moral para contensão da violência que domina a convivência entre os homens e entre os Estados. Para os fins de pacificação da sociedade contemporânea, "evitar a violência é mais importante que evitar a injustiça. E nenhuma tentativa de aumentar a justiça pode ser juridicamente admissível, uma vez que isso mina a diferença entre violência e direito, além de que provoca o risco de transformar direitos estabelecidos em violência institucionalizada". ${ }^{15}$

Para tanto, as vias jurídicas e políticas institucionais são formalmente necessárias, em especial após as atrocidades cometidas pelo regime nazista na Segunda Guerra Mundial, para a própria barreira à violência e, em situações mais extremas, para analisar a justificativa de um ataque a outro país ou de um conflito armado interno. E é com este intuito que se deve prestar atenção às normativas oriundas da $\mathrm{ONU}$ - ainda que sua reforma seja algo em discussão atualmente -, e também às regras de direitos internacional humanitário, especialmente no que tange ao chamado "uso da força preventiva" e às inspeções com o propósito de desarmamento. Nesse sentido, os direitos humanos lato sensu se constituem em uma orientação normativa decisiva para a distribuição do poder visando uma democracia de aspecto cosmopolita como imaginou Kant. ${ }^{16}$

15 KERSTING, Wolfgang. Hobbes, Kant, a Paz Universal..., p.7.

16 Ver: KANT, Immanuel. A paz perpétua $e$ outros opúsculos. Lisboa: Edições 70, 1995. 


\section{A IMPORTÂNCIA DO DIREITO INTERNACIONAL HUMANITÁRIO PARA SOLUÇÃO E PREVENÇÃO DOS CONFLITOS ARMADOS}

Ironicamente o senso comum tende a confundir as concepções de intervenção humanitária com a atuação do direito internacional humanitário. Na solução de controvérsias internacionais não causa surpresa o fato da ONU ter dado extrema credibilidade ao direito internacional humanitário, desde as experiências dos Julgamentos de Nuremberg depois da Segunda Guerra Mundial, até o estabelecimento pelo Conselho de Segurança, em maio de 1993, do Tribunal Internacional para a ex-Iugoslávia (ICTY), em Haia na Holanda, e em novembro de 1994, do Tribunal Internacional para Ruanda (ICTR), na Tanzânia na África. Ambas as instâncias jurisdicionais internacionais se valeram das quatro Convenções de Genebra de 1949, assim como da Convenção para Prevenção e Punição contra o crime de genocídio, de 1948, oriunda das Nações Unidas, com o intuito de julgar e punir os eventuais. ${ }^{17}$

Melhor explicando, o direito internacional humanitário ${ }^{18}$ parte da idéia de que os conflitos entre as nações ou entre grupos particulares sempre existiram e sempre existirão, ainda que não esteja na base de sua concepção fundamental a noção de que

17 ZIRING, Lawrence; RIGGS, Robert E.; PLANO, Jack C. The United Nations..., p. 313.

18 Sobre o assunto ver: SASSÒLI, Marco; BOUVIER, Antoine A. How does law protect in war? Cases, documents and teaching materials on contemporary practice in international humanitarian law. Geneva: International Committee of the Red Cross, 1999. a guerra seja sempre necessária para a manutenção da paz. Ao contrário, apesar de todos os esforços, tem se mostrado difícil evitar a guerra, de maneira que acaba sendo necessário limitar os sofrimentos desnecessários cometidos durante os conflitos. Assim, são as partes envolvidas em um conflito que devem respeitar as normas de direito internacional humanitário, o que significa não exclusivamente Estados, mas também todos os combatentes e participantes que representem ou não um Estado. Nesse sentido, suas normas se destinam aos chamados conflitos armados internacionais - por exemplo, a luta de um povo contra a dominação colonial, a ocupação estrangeira ou um regime racista -, e aos conflitos armados internos, situações que ocorrem no interior de um país, como o caso típico das guerras civis.

Para tanto, desde seu nascimento, em 1864 (portanto anterior ao chamado direito internacional dos direitos humanos), com a gênese de um Comitê Internacional neutro, conhecido por Cruz Vermelha, pelo médico suíço Jean Henri Dunant, vem regendo, a partir de dois blocos normativos, as situações de guerra: "direito de Genebra" - que diz respeito à proteção das vítimas -, "direito de Haia" - que trata dos meios e métodos de combates -, além do chamado "direito misto" - que envolve situações como a proteção dos bens culturais em tempos de guerra e o desarmamento.

Assim, são conceitualmente considerados tratados de direito internacional humanitário ${ }^{19}$ :

${ }^{19}$ COMITÊ INTERNACIONAL DA CRUZ VERMELHA. Disponível em: <http://www.icrc.org/ home>. Acessado em: 11 mar. 2006; MINISTÉRIO DAS RELAÇÕES EXTERIORES. Disponível em: $<$ http://www.itamaraty.gov.br/home>. Links temáticos. Acessado em: 11 mar. 2006. 
quatro Convenções de Genebra de $1949^{20}$ I. para a melhoria das condições dos feridos e enfermos das forças armadas em campanha, II. para a melhoria das condições dos feridos, enfermos e náufragos das forças armadas no mar, III. relativa ao tratamento dos prisioneiros de guerra, IV. relativa à propriedade dos civis em tempos de guerra -; Convenção da Haia para a proteção de bens culturais em conflitos armados ${ }^{21}$ Protocolo de $1954 ; 22$ Protocolo de $1999 ;{ }^{23}$ Convenção sobre a proibição do desenvolvimento, a produção e a destruição de armas biológicas e tóxicas de 1972; ${ }^{24}$ Convenção sobre a proibição do uso de técnicas de modificação ambiental para fim militar ou outros fins hostis de 1976; ${ }^{25}$ Protocolos Adicionais I (sobre conflitos armados internacionais) e II (sobre conflitos armados não internacionais) de 1977; ${ }^{26}$ Convenção sobre proibição e restrições do emprego de certas armas convencionais que causam danos excessivos de 1980, ${ }^{27}$ com 05 Protocolos Adicionais - I. que diz respeito a fragmentos não localizáveis, ${ }^{28}$ II. que trata das proibições do emprego de minas e armadilhas, de $1996,{ }^{29}$ III. que fala das armas

\footnotetext{
${ }^{20}$ Ratificadas pelo Brasil em 29 de setembro de 1957.

${ }^{21}$ Ratificada pelo Brasil em 12 de setembro de 1958.

${ }^{22}$ Ratificado pelo Brasil em 12 de setembro de 1958.

${ }^{23}$ Ratificado pelo Brasil em 2005.

${ }^{24}$ Ratificada pelo Brasil em 27 de fevereiro de 1973.

${ }^{25}$ Até o presente momento (abril de 2006) não ratificada pelo Brasil.

${ }^{26}$ Ratificados pelo Brasil em 05 de maio de 1992.

${ }^{27}$ Ratificada pelo Brasil em 03 de outubro de 1995.

${ }^{28}$ Ratificado pelo Brasil em 03 de outubro de 1995.

${ }^{29}$ Ratificado pelo Brasil em 04 de outubro de 1999.
}

incendiárias, ${ }^{30} \mathrm{IV}$. que trata das armas de laser cegantes, de $1995 ;^{31}$ V. que diz respeito aos resíduos de explosivos de guerra, de $2003^{32}$-; Convenção sobre a proibição do desenvolvimento, produção e destruição de armas químicas de 1993; ${ }^{33}$ Convenção sobre a proibição do emprego, armazenamento, produção e transferência de mina anti-pessoal e sua destruição (Tratado de Ottawa) de $1997 ;{ }^{34}$ Estatuto de Roma de 1998; ${ }^{35}$ Protocolo facultativo para a ausência de crianças nos conflitos armados de $2000 .^{36}$

A partir deste amplo quadro normativo, visualiza-se a necessidade de se dar maior importância ao direito internacional humanitário, não só quando o conflito já se estabeleceu ou após o seu término, mas em especial como mecanismo de prevenção para a sua não ocorrência, como força de pressão moral que é um dever da sociedade internacional, em conjunto com as populações civis e militares dos Estados, para o comprometimento de todos com a manutenção permanente da paz.

\footnotetext{
${ }^{30}$ Ratificado pelo Brasil em 03 de outubro de 1995.

${ }^{31}$ Ratificado pelo Brasil em 04 de outubro de 1999.

${ }^{32}$ Até o presente momento não ratificado pelo Brasil.

${ }^{33}$ Ratificada pelo Brasil em 13 de março de 1996.

${ }^{34}$ Ratificada pelo Brasil em 30 de abril de 1999.

35 Ratificado pelo Brasil em 20 de junho de 2002, trata da criação do Tribunal Penal Internacional, e conjuga elementos que dizem respeito ao direito internacional humanitário, em especial no seu artigo 8. ${ }^{\circ}$, não sendo considerado propriamente um tratado específico desta área, em virtude da amplitude de suas normas, que acabam abarcando os direitos humanos como um todo.

${ }^{36}$ Ratificado pelo Brasil em 08 de março de 2004.
} 


\section{O RETORNO DO IDEALISMO ÀS RELAÇÕES INTERNACIONAIS}

A queda do "Muro de Berlim" em 1989, o desmembramento da União Soviética em meados de 1991, e mais recentemente, o "ataque às torres gêmeas" em 11 de setembro de 2001, engendraram uma era de modificações quase instantâneas no mundo contemporâneo. Embora estes eventos não tenham relação direta com o plano de atuação e tampouco tenham ocorrido no âmbito das Nações Unidas, trouxeram reflexos decisivos para o futuro da organização de caráter mundial. $\mathrm{Na}$ onda da Guerra Fria, cidadãos e diplomatas expressaram otimismo em relação ao papel multilateral das Nações Unidas na então chamada "nova ordem mundial". Porém, naquele momento o papel da instituição pouco contribuiu para o embate entre um mundo bipartido por questões ideológicas já amplamente debatidas.

Entretanto, estes referidos três emblemáticos recentes eventos históricos colocaram em questionamento a tarefa primeira do sistema das Nações Unidas - qual seja, "a segurança da humanidade" - quando de sua criação, no final da Segunda Guerra Mundial, com a assinatura da Carta das Nações Unidas em 26 de junho de 1945. Neste sentido, duas guerras mundiais, o holocausto e o advento da era nuclear contribuíram para que o mundo experimentasse uma nova maneira de organizar os Estados a fim de evitar a guerra, tentativa já empreendida pela Liga das Nações no seu curto período de aproximadamente 20 anos de existência. A comunidade internacional rejeitou o isolacionismo e se comprometeu a tentar salvaguardar a paz que "razoavelmente" se estabelecera a custa das dolorosas consequiências de um mundo castigado por praticamente 33 anos de guerra intermitente.

O advento da Carta das Nações Unidas que inaugurou, no plano internacional, a abrangente positivação dos direitos humanos - transpôs, da teoria para a prática, em vários artigos, com uma amplitude que não tinha o Pacto da Sociedade das Nações, uma leitura "kantiana" ${ }^{37}$ dos direitos humanos e das relações internacionais, filosofia esta que também dominou a lógica dos estados entre os séculos XVII e XVIII. Vale dizer, admitiu a possibilidade da inserção operativa de uma razão abrangente da humanidade, que poderia, com o passar do tempo, conter a "razão de estado discricionária das soberanias", até então impeditivas da proteção jurídica internacional da pessoa humana.

Contudo, o realismo político ${ }^{38}$ - oposição teórica ao idealismo de base kantiana nas relações internacionais - como paradigma predominante nas relações internacionais entre 1950 e 1990, assinalado, em especial, pela relação bipolar conflituosa EUA-URSS,

37 Sobre o tema consultar: GUINSBURG, J. (Org.). A paz perpétua: um projeto para hoje. São Paulo: Perspectiva, 2004; KANT, Immanuel. A paz perpétua e outros opúsculos. Lisboa: Edições 70, 1995; NOUR, Soraya. À Paz Perpétua de Kant: filosofia do direito internacional e das relações internacionais. São Paulo: Martins Fontes, 2004.

${ }^{38}$ Sobre o assunto ver: ARON, Raymond. Paz e guerra entre as nações. Brasília: Ed. UnB, Instituto de Pesquisa de Relações Internacionais; São Paulo: Imprensa Oficial do Estado de SP, 2002; MORGENTHAU, Hans. J.; THOMPSON, Kenneth W. Politics among nations: the struggle for power and peace. 6th ed., New York: MacGraw-Hill Educational and Professional Publishers, 1985; NOUR, Soraya. À Paz Perpétua de Kant..., p.109-156. 
contribui, em virtude da batalha ideológica travada entre Leste e Oeste, durante um certo período, para o enfraquecimento das causas relacionadas à paz, segurança e aos direitos humanos. Ademais, esta seletividade geográfica, marcada por uma "dialética dos contrários", agravou ainda mais a desigualdade entre o Norte e o Sul do planeta, fazendo com que termos como "coexistência pacífica", "cooperação" e "integração" fossem alvo de ferozes críticas por parte dos intelectuais daquele momento.

Ressalta-se, entretanto, que não é nem simples tampouco linear a discussão dos fatores que têm levado, no processo histórico, à emergência e a consolidação da proteção jurídica internacional, no final do milênio, totalmente de espírito kantiano. Se por um lado, o tema dos direitos humanos tem sido, há muito, objeto de discussão de filósofos e juristas, em especial no tocante à característica da universalidade; por outro, o realismo político, que importou para as relações internacionais um paradigma estatocêntrico, na segunda metade do século XIX, contribuiu para a propagação de uma visão demasiado estruturalista do sistema jurídico internacional, deixando o ser humano em segundo plano em detrimento dos jogos de poder e do uso da força perpetrados pelos Estados. Consoante alerta Wolfgang Kersting:

De acordo com a compreensão contemporânea, a tarefa fundamental do direito não é assegurar a justiça, mas evitar a violência. $\mathbf{O}$ termo contrário a direito não é injustiça, mas violência (grifo nosso). Por isso, a injustiça não pode legitimar o uso da força. Só a destruição violenta do direito pode evocar a força de intervenção militar no sentido da autodefesa do direito. O hostis iniustus não é o anticristo, o inimigo que destrói as intenções do cristianismo ou pisa em cima dos valores do liberalismo ou da democracia. O hostis iniustus não é mau nem ergueu o império do mal. $\mathrm{O}$ hostis iniustus é muito mais o destruidor do direito - e isso é muito pior para seres humanos que têm que conviver com seres humanos sob condições feitas por seres humanos; ele é o anti-direito. Combatê-lo é um dever do direito. Se um governo submete seus cidadãos à violência, terroriza e persegue grandes partes da população, deixa-os morrer de fome e os deporta, afugenta-os do país, mata-os e os enterra em valas comuns, então uma intervenção militar é, de fato, justificada. ${ }^{39}$

Assim, após um período de "ataque frontal" aos efeitos negativos da modernidade uma nítida reação a características como individualidade exacerbada, autonomia absoluta da vontade, igualdade meramente formal, liberalismo econômico causador da exclusão em países já muito empobrecidos pela colonização, dentre outros inúmeros fatores passíveis de citação - nas relações contemporâneas, o momento atual exige uma reflexão para além da crítica pela crítica (por necessário, momento inicial, de revolta contra as causas e seus causadores), que, objetivamente, trate de evidenciar a situação mundial limítrofe.

Para Soraya Nour, "Kant apresentou as condições de possibilidade da paz; sua realização hoje depende da explicitação das condições de luta contra as relações hegemônicas que a destroem". ${ }^{40}$ Para tanto, é imprescindível o respeito às instituições jurídicas formais de caráter internacional, como as Nações Unidas, na medida que

${ }^{39}$ KERSTING, Wolfgang. Hobbes, Kant, a Paz Universal..., p.7.

${ }^{40}$ NOUR, Soraya. À Paz Perpétua de Kant..., p.195. 
congregam a opinião de vários Estados em cooperação por políticas de prevenção e de manutenção da paz. Se há ainda a dificuldade para que suas decisões tenham plena eficácia - como ocorreu com a invasão norte-americana no Iraque, afrontosa ao direito internacional -, tal fato não é argumento ético para que daqui para frente nenhuma decisão seja mais respeitada.

\section{CONSIDERAÇÕES FINAIS}

Conforme adverte Edward W. Said, ${ }^{41}$ há uma ampla discrepância hoje entre nossas culturas e sociedades e entre o pequeno grupo de pessoas que no momento governam estas sociedades. Nessa linha de raciocínio, raramente na história o poder ficou tão concentrado nas mãos de grupos tão minúsculos. Tal fato não se reduz a um critério de simples ausência de democracia, mas de absoluta subestimação da população governada e de regras de poder abertamente inspirada em teorias conspiratórias. Disto resulta a ausência de dois elementos decisivos para a sobrevivência da humanidade: a dignidade e a solidariedade.

Em tempos de paz, não há obstáculos para a consecução de plenos direitos, muito menos para a luta contra a intolerância e o desrespeito. $\mathrm{O}$ problema se agrava diante da complexidade que domina as relações contemporâneas. Atualmente sim é que se deve, ainda mais, refletir acerca do caos que assola a humanidade, porque a guerra, antes de tudo, aniquila toda e qualquer

41 SAID, Edward W. From Oslo to Iraq and the Road Map. New York: Pantheon Books, 2004, p.293-295. possibilidade de produção da vida em todos os seus sentidos.

Parafraseando Michael Walzer, ${ }^{42}$ “o mundo da guerra não é um lugar plenamente compreensível, muito menos satisfatório em termos morais. Dele não se pode, entretanto, escapar, se não houver uma ordem universal em que a existência de nações e povos já mais possa ser ameaçada. São inúmeras as razões para trabalhar por uma ordem dessa. A dificuldade é que às vezes não temos escolha a não ser lutar por ela."

\section{REFERÊNCIAS BIBLIOGRÁFICAS}

\section{Obras consultadas}

ALI, Tariq. Confronto de fundamentalismos: cruzadas, jihads e modernidade. Rio de Janeiro: Record, 2002.

ARON, Raymond. Paz e guerra entre as nações. Brasília: Ed. UnB, Instituto de Pesquisa de Relações Internacionais; São Paulo: Imprensa Oficial do Estado de SP, 2002.

BALDI, César Augusto (Org.). Direitos humanos na sociedade cosmopolita. Rio de Janeiro: Renovar, 2004.

BARRETO, Vicente de Paulo. Dicionário de filosofia do direito. São Leopoldo: Unisinos; Rio de Janeiro: Renovar, 2006.

BELL, Daniel E. East meets West: human rights and democracy in East Asia. Princeton, New Jersey: Princeton University Press, 2000.

CICV (Comitê Internacional da Cruz Vermelha). Normas fundamentais das Convenções de Genebra e de seus Protocolos Adicionais. Genebra, 1983.

FASULO, Linda. An insider's guide to the UN. USA: Yale Univesity Press; Vail-Ballou Press, 2004.

42 WALZER, Michael. Guerras Justas e injustas: uma argumentação moral com exemplos históricos. São Paulo: Martins Fontes, 2003, p.556-557. 
GARAUDY, Roger. O ocidente é um acidente: por um diálogo das civilizações. Rio de Janeiro: Salamandra, 1978.

GUINSBURG, J. (Org.). A Paz perpétua: um projeto para hoje. São Paulo: Perspectiva, 2004.

HOBSBAWN, Eric J. A era dos extremos: o breve século XX: 1914 - 1991. São Paulo: Companhia das Letras, 1995.

KANT, Immanuel. A paz perpétua e outros opúsculos. Lisboa: Edições 70, 1995.

KERSTING, Wolfgang. Hobbes, Kant, a Paz Universal e a guerra contra o Iraque. Kant eprints, Vol. 3, n. 2, 2004.

KERSTING, Wolfgang. Universalismo e direitos humanos. Porto Alegre: EDIPUCRS, 2003.

\section{MORGENTHAU, Hans. J.; THOMPSON,}

Kenneth W. Politics among nations: the struggle for power and peace. $6^{\text {th }}$ ed., New York:

MacGraw-Hill Educational and Professional Publishers, 1985.

NOUR, Soraya. À Paz Perpétua de Kant: filosofia do direito internacional e das relações internacionais. São Paulo: Martins Fontes, 2004.

SAID, Edward W. Cultura e política. São Paulo: Boitempo, 2003.

SAID, Edward W. From Oslo to Iraq and the Road Map. New York: Pantheon Books, 2004.

SAID, Edward W. Orientalismo: o oriente como invenção do ocidente. São Paulo: Companhia das Letras, 1990.
SASSÒLI, Marco; BOUVIER, Antoine A. How does law protect in war? Cases, documents and teaching materials on contemporary practice in international humanitarian law. Geneva: International Committee of the Red Cross, 1999. WALZER, Michael. Guerras Justas e injustas: uma argumentação moral com exemplos históricos. São Paulo: Martins Fontes, 2003.

WEISS, Thomas G.; FORSYTHE, David P.; COATE, Roger A. The United Nations and changing world politics. $4^{\text {th }}$ ed. Colorado: Westview Press, 2004.

ZIRING, Lawrence; RIGGS, Robert E.; PLANO, Jack C. The United Nations: International organization and world politics. $4^{\text {th }} \mathrm{ed}$. Belmont, USA: Wadsworth, 2005.

\section{Sites consultados}

COMITÊ INTERNACIONAL DA CRUZ

VERMELHA. Disponível em: <http://

www.icrc.org/home>. Acesso em: 11 mar. 2006

MINISTÉRIO DAS RELAÇÕES

EXTERIORES. Disponível em: <http:// www.itamaraty.gov.br/home>. Links temáticos. Acessado em: 11 mar. 2006.

ORGANIZAÇÃO DAS NAÇÕES UNIDAS. Main UN Bodies. Disponível em: <http:// www.un.org/icty/index.html> Acessado em: 20 abr. 2006.

\section{ORGANIZAÇÃO DOS PAÍSES} EXPORTADORES DE PETRÓLEO.

Disponível em: <http://www.opec.org/home>. Acessado em: 03 abr. 2006. 